\title{
Modelling 132 kV substation for surge arrester studies
}

\begin{abstract}
Insulation coordination models are an essential part of power system studies and are used to determine the performance of a transmission line or substation. This paper generalizes the guidelines and parameters to be used in modelling the substation and in performing the analysis on the prediction of the transformer damage. Modelling parameters and the substation layout design are based and adapted from 132/11 kV Simpang Renggam - Ayer Hitam substation in Johor Baharu, Malaysia, courtesy of the Tenaga Nasional Berhad (TNB). The model is based on the single phase line model, as was suggested by the IEEE, to be adequate to represent the substation in transient analysis simulation. Extensive analyses on the placement of the surge arresters at the substation and a prediction of the transformer damage are also presented. The results obtained from this analysis are then compared with the suggested Basic Lightning Insulation Level (BIL) by the TNB, according to the standards, for assessing the percentage of transformer damage and optimizing the substation performance in terms of its reliability and cost effectiveness.
\end{abstract}

Keyword: Insulation coordination; Ligtning; Basic lightning insulation level (BIL); Surge arrester 